\title{
O HAITI E SUAS MIGRAÇÕES ${ }^{1}$
}

Kassoum Dieme ${ }^{2}$

RESUMO: Este artigo aborda as migrações haitianas ao longo da história, baseando-se apenas nos grandes fluxos para/ou do Haiti. De um país particularmente marcado pela imigração antes de sua independência, o Haiti se transforma num país que registra muito mais saídas de pessoas para viver fora do país do que chegadas em território nacional. Entre os principais destinos dos grandes fluxos da emigração haitiana, o Brasil aparece como o mais recente, tendo recebendo haitianos com base numa política exclusiva de acolhimento institucional (humanitária) vigente de janeiro de 2012 a outubro de 2017. Diante disso, o texto se detém sobre as Resoluções $\mathrm{N}^{\circ} 97 / 12$ e $\mathrm{N}^{\circ} 08 / 06$, acionadas por razões humanitárias, levantando questões acerca das condições de existência e de permanência de haitianos no Brasil ao longo dos últimos oito anos.

PALAVRAS-CHAVE: Migrações do Haiti; Brasil e os haitianos; Condições de existência; Permanência.

\section{HAITI AND ITS MIGRATIONS}

\begin{abstract}
This article addresses Haitian migrations throughout history, discussing mainly the four largest flows of immigrants leaving or coming to Haiti. From a country particularly marked by immigration before its independence, Haiti became since then a country that registers a larger outflow of people from the country than arrivals. Among the main destinations of these larger outflows of Haitians, Brazil becomes their latest main destination, continuing to receive Haitians on the basis of a policy of exclusive

\footnotetext{
${ }^{1}$ Este artigo é uma parte atualizada da minha dissertação de mestrado, financiada pelo CNPq, orientada pelo Professor Dr. Mário Augusto Medeiros da Silva e defendida em 30 de novembro de 2016 no PPGS do Instituto de Filosofia e Ciências Humanas da Universidade Estadual de Campinas

${ }^{2}$ Mestre em Sociologia pela Universidade Estadual de Campinas. E-mail: kdieme@hotmail. com
} 
institutional (humanitarian) reception which ran from January 2012 to October 2017. In this regard, this article reflects on Resolutions No. 97/12 and No. 08/06, mobilized for humanitarian reasons, raising questions about the conditions of existence and permanence of Haitians in Brazil over the last eight years.

KEYWORDS: Haitian migrations; Brazil and the Haitians; Conditions of existence ; permanence.

\section{INTRODUÇÃO}

\section{IMIGRAÇÃO NO HAITI?}

A história do território que hoje corresponde à República do Haiti é tanto marcada pela emigração quanto pela imigração. Esta ocupa um lugar fundamental na história deste país. Os fluxos de europeus e africanos com destino ao Haiti duraram séculos (de 1492 à véspera da Revolução Haitiana de 1791) e foram, no seu conjunto, muito intensos, particularmente no século XIX. Os espanhóis foram os primeiros neste processo, iniciado já em 1492. Segundo Peregalli (1998), suas relações com os povos americanos foram expressivamente marcadas tanto pela violência quanto pela crueldade. Práticas dessa natureza levaram à eliminação de milhões de ameríndios da ilha de Santo Domingos entre 1492 e 1514 (PEREGALLI, 1998). Seguy (2014), por sua vez, destaca que no que tange à colonização do Haiti, os franceses (1697-1803) sucederam os espanhóis (1492-1697), deixando um balanço negativo em termos ambientais. Olhando para as disputas que houve entre a Espanha e a França, seja ligadas à ocupação ou à permanência, percebe-se que o Haiti era, antes mesmo de ser a Pérola das Antilhas, um território cobiçado, uma área de atração, não de expulsão.

Embora marcadas pela exploração e pela extrema violência, as colonizações favoreceram também migrações em pequenas, médias e longas distâncias. Por um lado, ajudaram a dizimar povos, e, por outro, favoreceram o povoamento de outros territórios. No caso do Caribe, Hall (2003) assinala que as populações que ali vivem atualmente são oriundas de outros lugares. É imprescindível sublinhar que, no caso do Haiti, a presença da população negra foi fruto de um processo de deslocamentos 
forçados, que começou na África, e que tinha em vista o trabalho forçado, sob a direção e em benefício de brancos europeus. Télémaque (2012) fala de "meio milhão de escravos negros transplantados de Senegal e de Dahomey" sobre os quais reinavam quase 40 mil plantadores, brancos, nos séculos XVII e XVIII. Citando Moreau de Saint-Méry, Seguy (2014, p.135) mostra que a imigração compulsória de africanos negros na véspera da Revolução Haitiana era intensa. Assim, "em 1790, dois terços da população de São Domingos teria nascido na África". C.L.R. James afirma que: "entre 1764 e 1771 a média das importações de escravos oscila entre 10.000 e 15.000 por ano. Em 1786, importou-se 27 000, e a partir de 1787 a colônia absorvia mais de 40000 escravos por ano" (JAMES apud SEGUY, 2014, p.135).

A imigração na história do Haiti era predominantemente de negros, que foram, segundo Pean, citado por Seguy (2014, p.135-136), escravizados e responsáveis pela produção de grandes quantidades de riquezas para franceses. "Assim, em 1789, São Domingos produzia 180 milhões de libras de mercadoria, muito mais que todas as colônias inglesas e espanholas das Antilhas, as quais, juntas, produziam em torno de 117 milhões de libras" (Ibid. p.136). É dentro desse contexto de produção de riquezas sugadas pela França que o Haiti foi coroado "Pérola das Antilhas" (SEGUY, 2014, p.36).

A Revolução Haitiana, um marco da história do Haiti, da América e do mundo moderno - e que é muitas vezes deliberadamente marginalizada -, e os vestígios da configuração étnico-racial construída durante a colonização, ${ }^{3}$ são devedoras de um processo migratório forçado atrelado a uma superexploração do trabalho de escravizados da África negra em território caribenho que, no entanto, souberam se organizar e derrotar um sistema parasitário que, paradoxalmente, os desumanizava.

É preciso assinalar a imigração em menor quantidade, no Haiti independente politicamente, de populações que não vieram da Europa

\footnotetext{
${ }^{3}$ Segue a então pirâmide social na base da qual estão os Escravos negros, antes dos quais estão os Marrons, Sang-malés, Mulâtres, Petits blancs, Grands blancs, e no topo os Affranchis (COTINGUIBA, 2014, p. 74-75). Essa configuração deixou marcas no país que acabara de conquistar sua independência, embora o Haiti tenha se reconhecido como uma "Nation Nègre".
} 
nem da África Negra, e que não estavam em busca de riquezas materiais, mas sim, como afirmam Cotinguiba (2014) e Handerson (2015), de proteção e de liberdade, como foi o caso com imigrantes do Oriente Médio $^{4}$ e de negros estadunidenses, discutidos respectivamente pelos autores mencionados.

Diante do exposto, lembrando que a população autóctone era praticamente extinta, fica evidente que o Haiti foi ao longo de séculos um território de imigração. Omitir este fato é também perder de vista um dos fenômenos que estão na base da história da chamada primeira República Negra. A imigração em questão começou com a vinda de europeus em busca de produtos, seguida da de africanos forçados a imigrar para trabalhar compulsoriamente, de modo a sustentar os negócios dos seus exploradores e supostos donos. Omitir a imigração ao tratar da migração haitiana seria, portanto, de uma inconveniência notável. Cotinguiba (2014, p.82), citando Jacobson (2003), assinala que "em quase todo o século XIX, o país [Haiti] se tornou o lugar de destino de migrantes, especialmente escravos" evadidos. Cabe ainda assim ressaltar que o Haiti, tornado independente em 1804, tornou-se predominantemente um país de emigração, embora não tenha deixado de receber pessoas de outras partes do mundo.

\section{A EMIGRAÇÃO HAITIANA}

Os haitianos não esperaram conquistar sua independência política para emigrar. Embora não fizesse parte de seus grandes fluxos emigratórios, a saída de haitianos para a França foi, como sugere Handerson (2015), um marco da emigração haitiana. Estas idas para a França são desdobramentos patentes do processo de colonização. Indo além do mencionado na parte anterior, a colonização se expressa não só pela imigração, mas também pela emigração. O idioma imposto, que costuma ser um dos efeitos desse

\footnotetext{
${ }^{4}$ No caso dos libaneses ver : L'implantation de la communauté arabe en Haïti vue par JeanHenri Céant. Publicado em: 04/02/2014. Disponível em: <http://mediamosaique.com/ General/2014-02-04-21-19-34.html> Acesso em: 17/12/2015, e Les Arabes Haïtiens. Disponível em: <https://www.youtube.com/watch?v=Vm8M8_o9NJ0>. Acesso em: 08/10/2015.
} 
processo, pode também acabar vindo a ser um fator de aproximação entre povos colonizadores e povos colonizados. É neste contexto que se entende a saída dos primeiros haitianos, referida por Handerson (2015), para a França em busca de formação acadêmica, antes mesmo da conquista da independência política pelo Haiti ${ }^{5}$. Trata-se notadamente dos affranchis e dos mulâtres: ${ }^{6}$

considerados como parte da elite e proprietários de terras, que mandavam seus filhos, desde o final do século XVIII, e também, posteriormente, no século XIX, após a Independência do Haiti, para realizar seus estudos na França. Foram inúmeros os escritores, advogados e médicos haitianos formados na França. (HANDERSON, 2015, p.68)

Se a França metropolitana aparece como o primeiro destino da emigração de haitianos, notadamente dos mulâtres em busca de estudo (HANDERSON, 2015; SEGUY, 2014), Handerson (2015) mostra que ela não figura entre os quatro maiores fluxos de saída de haitianos para o estrangeiro. Estes ocorrem a partir do século XX e são motivados principalmente pela busca por trabalho. Outros fatores, como a proximidade geográfica, a economia das nações almejadas, as influências política e cultural de outros Estados e os motivos ambientais, ajudam a entender a emigração de haitianos ao longo dos últimos séculos.

Em ordem cronológica, o primeiro grande fluxo da emigração haitiana, que remonta ao início do século XX, foi dirigido para a República Dominicana e para Cuba. Os emigrantes eram trabalhadores em busca de oportunidade de trabalho em empresas de cana-de-açúcar estadunidenses instaladas nestes países (SCARAMAL, 2006; HANDERSON, 2015) ${ }^{7}$.

${ }^{5}$ A relação migração/colonização é mostrada por Duroux (2011), embora o trabalho em questão mencione apenas os fluxos das antigas colônias para as antigas metrópoles.

${ }^{6}$ Os "affranchis [eram brancos], burocratas ligados diretamente aos representantes reais, o governador e o intendente. [...] os mulâtres e os sang-malés (libertos) [eram] frutos das relações sexuais entre brancos e negras." (SCARAMAL apud COTINGUIBA, 2014, p.74-75)

${ }^{7}$ Nos primeiros anos do século passado "tanto as Bahamas quanto as Ilhas Turks e Caicos também receberam vários contingentes de migrantes haitianos, com reincidência de fluxos nas 
Essa mobilidade internacional de haitianos ocorre no período em que "as forças armadas americanas ocuparam o Haiti (1915-19[34]) e a República Dominicana (1912-1924) simultaneamente." (HANDERSON, 2015, p.69). A presença respectiva de 22.579 e 19.065 haitianos nos anos 1970 em Cuba e na República Dominicana (VILLA, 1996) teria alguma relação com essas ocupações. Nesse sentido, cabe perceber essas emigrações haitianas como fruto de um processo de "envio" para o trabalho que envolveu intervenção política. A emigração haitiana para a República Dominicana é um processo ainda em curso. Vista como economicamente mais desenvolvida, e também por conta da contiguidade geográfica, ela tem atraído milhares de haitianos, cuja integração social, contudo, é ainda bastante problemática. Scaramal (2006) sublinha que a República Dominicana é um dos países em que há maior presença de haitianos, e certamente aquele em que estes são historicamente mais hostilizados, isto é, onde se manifesta mais intensamente o chamado "anti-haitianismo".

No que se refere à emigração de haitianos para os Estados Unidos, Cotinguiba (2014) parte do estudo de Jacobson (2003) para mostrar que este é um destino emigratório de haitianos desde o último quarto do século XVIII, e que alguns deles fundaram vilarejos no século XIX no novo país. Para Handerson (2015), a ida de haitianos para os Estados Unidos corresponde ao segundo grande fluxo migratório do Haiti. O autor destaca não somente a ocupação estadunidense do Haiti entre 1915 e 1934, mas também a influência cultural exercida, como elementos básicos para se entender o processo de sua constituição em grande fluxo. A educação formal e a religiosidade foram dimensões claramente impactadas, tanto por conta da obrigatoriedade do ensino do idioma inglês na década de 1940 quanto do crescimento das igrejas protestantes estadunidenses em território haitiano. Estas ferramentas despertam o sentimento de pertencimento a uma só comunidade, seja ela linguística ou religiosa - o que pode ser um fator, mesmo que entre outros, a provocar migrações expressivas. Handerson (2015, p.70) afirma que "na década de 1950, a elite haitiana mandava seus filhos estudarem nos Estados Unidos e alguns dos

décadas de 1970 e 1990. (...) [Havia haitianos nas Guianas e na Venezuela] nas últimas décadas do século XX” (SCARAMAL, 2006, p.96). 
agricultores que já haviam residido em Cuba ou na República Dominicana viam os Estados Unidos como uma nova possibilidade para emigrar". Cabe ressaltar que ocupações, tal como colonizações, de países por outros têm provocado migrações internacionais nos dois sentidos. Não há ocupação, nem colonização, sem migração, ainda que possa ser apenas temporária. Os casos das respectivas relações da França e dos Estados Unidos com o Haiti o demonstram cabalmente.

As causas da saída de haitianos do seu país para os Estados Unidos não se esgotam na influência cultural nem na ocupação militar. Conjunturas políticas especificamente nacionais figuram também como fator significativo para a emigração de milhares de haitianos para o fluxo em questão. Foi o caso da época das ditaduras dos Duvalier. Cédric Audebert sublinhou que

A autoproclamação de "Presidente vitalício" de François Duvalier em 1964 assustou os intelectuais e a classe média negra (médicos, advogados, professores), que não demoraram para ir ao exílio. Entre 1957 - o ano de ascensão de Duvalier ao poder - e 1963, 6.800 haitianos foram para os Estados Unidos com visto de imigrantes e outros 27.300 com visto temporário. Entre o ano da autoproclamação em 1964 até o ano da sua morte em 1971, os serviços de imigração estadunidense registraram 40.100 imigrantes e 100.000 não-imigrantes oriundos do Haiti. (AUDEBERT apud HANDERSON, 2015, p.70).

A busca por trabalho num país cuja moeda garante maior poder de compra e que apresenta maiores possibilidades de emprego e renda é um dos fatores de atração que os Estados Unidos têm sobre cidadãos de diversas partes do mundo, particularmente sobre aquelas fronteiriças e economicamente menos desenvolvidas. Entre estes podemos citar como exemplos os mexicanos, os brasileiros e os haitianos, com pelo menos um milhão de seus respectivos cidadãos naquele país. Contudo, ainda que os Estados Unidos sejam o destino privilegiado pelos migrantes haitianos, o processo não ocorre de forma pacífica. Em seu estudo, Scaramal (2006) 
menciona altíssima taxa de devolução de haitianos que tentavam entrar naquele país por embarcações entre 1981 e 1991, um período parcialmente marcado pela ditadura e, como veremos adiante, pela instabilidade política. ${ }^{8}$ A emigração de haitianos para o Canadá, e em especial rumo à capital de sua parte de expressão francesa, é parte do segundo grande fluxo emigratório, que é anterior à década de 1940 e inicialmente relacionado à busca de formação. O perfil dos migrantes sofre mudanças nas décadas subsequentes, durante as quais profissionais e intelectuais emigraram tanto para o Quebec quanto para outras partes do mundo (HANDERSON, 2015). O autor afirma, no tocante ao Quebec/Canadá:

Desde a década de 1930, alguns estudantes haitianos, particularmente seminaristas e agrônomos, iam para o Quebec realizar os estudos. Durante a década de 1950 e início de 60, houve mudanças no perfil migratório: eram músicos que levavam os ritmos antilhanos para o local. Na segunda metade da década de 1960, houve um grande êxodo de haitianos para o Canadá, particularmente Quebec, fugindo da ditadura. Segundo Icart (2004, p.1), muitos foram convidados para ocupar cargos importantes pela grande expansão dos serviços sociais, de saúde e de educação. [...] Havia mais de duzentos médicos haitianos em Quebec e quase mil professores. Na década de 1980, um programa especial do Governo de Quebec concedeu o estatuto de imigrante a 4 mil haitianos que já estavam no local (HANDERSON, 2015, p.70-71).

Em 2001, o número de pessoas oriundas do Haiti que viviam no Canadá ultrapassou o total de 82.000 , sendo que $90 \%$ delas residiam em Quebec, e 83\% em Montreal (STATISTIQUE CANADA, 2007). Estes dados mostram que o idioma foi, também no caso dessa migração, um fator a levar em consideração.

\footnotetext{
${ }^{8}$ Em suma, os dois países com maiores presenças de haitianos são paradoxalmente os que se mostram menos acolhedores, seja por saturação seja por aplicação de políticas migratórias abusivas, como sugerido em entrevista por Márcia Oliveira (2016). Políticas dessa natureza foram alvo de críticas de Basso (2013), no tocante ao continente europeu.
}

Temáticas, Campinas, 25, (49/50): 17-48, fev./dez. 2017 
Handerson (2015) situa o começo do terceiro fluxo da emigração haitiana na última década do século XX. Este fluxo, cujo destino principal foram os Estados Unidos, ocorre num período de instabilidade política, que sucedeu a uma época ditatorial também marcada pela insegurança e pelo medo e terror provocados pelo Estado, bem como pela emigração de milhares de pessoas. Em Baptiste (2015), pode-se ver que, de 1987 a 1996, o tempo maior de permanência no cargo da Presidência da República não passou dos 18 meses.

Em 1991, Jean-Bertrand Aristide, presidente eleito e esperança dos menos favorecidos da sociedade haitiana (Haiti-Référence), sofreu um golpe de Estado depois de algum tempo no cargo. Sua retirada do país naquele contexto gerou a saída de dezenas de milhares de haitianos de sua República. Foi nesse período que "[...] aproximadamente 46.000 boat people foram interceptados em alto mar e conduzidos aos campos de detenção de Guantanamo Bay em Cuba. Alguns ficaram presos por mais de um ano" (HANDERSON, 2015, p.73). Wooding e Moseley-Williams (apud HANDERSON, 2015, p.73) estimam que "mais de 100.000 haitianos deixaram o Haiti na época da deportação do ex-presidente Jean-Bertrand Aristide, no ano de 1991".

Emigrações forçadas provocadas pela instabilidade política no país envolveram até alguns dos que chegaram à magistratura suprema. É o caso do ex-Presidente Aristide, que se refugiou nos Estados Unidos entre 1991 e 1994 e se exilou na África do Sul entre 2004 e 2011 após ter renunciado sob protestos. ${ }^{9}$ Antes dele, Michel Domingue, Lysius Félicité Salomon e Nord Alexis, por exemplo, que governaram o país, respectivamente, de junho de 1874 a abril de 1876 , de outubro de 1879 a agosto de 1888 e de dezembro de 1902 a dezembro de 1908, viveram em exílio ${ }^{10}$.

Se a imigração haitiana teve o trabalho forçado, a exploração de centenas de milhares de negros por algumas dezenas de milhares de brancos,

\footnotetext{
${ }^{9}$ Ver: Ex-presidente haitiano Jean-Bertrand Aristide está em prisão domiciliar. Disponível em: $<$ http://www1.folha.uol.com.br>. Acesso em 30 de agosto de 2017.

${ }^{10}$ HAITI-REFERENCE. Liste des Chefs d'État Haitiens. Disponível em: < http:/ / haiti-reference. $\mathrm{com} / \mathrm{pages} / \mathrm{plan} /$ histoire-et-societe/notables/chefs-detat/ $>$. Acesso em 30 de agosto de 2017.
} 
o racismo e a produção de grandes quantidades de mercadorias para a França como elementos que a caracterizaram, sua emigração esteve, desde a independência até o fim do século XX, estreitamente ligada à economia (busca por trabalho) e à política (por conta do isolamento infligido, da instabilidade das instituições do Estado, das políticas econômicas impostas ao país, das suas ditaduras, das ocupações militares). Sassen (2010) afirma que as dificuldades causadas às famílias, empresas e governos no Sul global por uma política macroeconômica têm provocado fluxos migratórios. No que tange a essa política, Galeano (2014, p.462; tradução nossa) constata: "país submisso às ordens do Banco Mundial e do Fundo Monetário, o Haiti havia obedecido suas instruções sem murmúrios", para depois concluir que tais instruções provocaram migrações de camponeses, cujas mortes em águas do Mar do Caribe não foram devidamente noticiadas.

Isto sugere que, tanto para Galeano (2014) quanto para Sassen (2010), buscar alcançar o Norte global se torna uma estratégia de sobrevivência. Nas palavras da segunda autora:

Inserir-se nas migrações de trabalho globais torna-se cada vez mais uma estratégia de sobrevivência dos habitantes destes países [do "Sul global"] ${ }^{11}$, para seus governos mediante transferências de dinheiro dos migrantes e para os 'empresários' do tráfico de pessoas - sobretudo de mulheres (SASSEN, 2010, p.27).

Aliás, no caso do Haiti, as remessas atingiram em torno um quarto do PIB $(24,8 \%)$ ao longo das últimas décadas. ${ }^{12}$ É preciso somar às causas estruturais da migração aquelas endógenas, específicas, embora sem que com isso se ignore a porosidade da fronteira que divide o micro do macro, desde os primeiros anos de independências.

De acordo com Handerson (2015, p.74), hoje "chèche lavi: busca daquilo não encontrado no país, isto é, estabilidade política e

${ }^{11}$ Tanto o Sul quanto o Norte global se referem, não a regiões geográficas, mas a conjuntos políticos (SASSEN, 2010, p. 27).

${ }^{12}$ O valor é de 109 milhões em 1995, de 876 milhões de dólares em 2005, e estimado em 1,5 bilhão de dólares em 2011 (FERNANDES; CASTRO, 2014, p. 11).

Temáticas, Campinas, 25, (49/50): 17-48, fev./dez. 2017 
socioeconômica, serviços de saúde, infraestrutura, estudo, trabalho, dinheiro para enviar aos próximos" está na base da emigração de haitianos. O que, a nosso ver, não invalida as referidas análises de Sassen (2010) e Galeano (2014), sobretudo quando se considera o primeiro grande fluxo da emigração haitiana.

Embora não tenham sido os únicos destinos da emigração haitiana, a República Dominicana, Cuba, Estados Unidos, Canadá e Brasil estão entre os territórios que receberam maiores números de haitianos. A terceira parte deste artigo trata da imigração de haitianos no Brasil a partir de 2010, processo que, para Handerson (2015), é parte destacada do quarto grande fluxo de mobilidade destes cidadãos para fora do seu país.

\section{EMIGRAÇÃO HAITIANA PARA O BRASIL}

A emigração haitiana para o Brasil ocorre antes do final do século XX. Essa presença é mencionada por Villa (1996) e Télémaque (2012), porém, não chamou a atenção das sociedades de origem nem de acolhimento. Importa, portanto, destacar que tanto o terremoto que abalou o Haiti em janeiro de 2010 quanto a MINUSTAH ${ }^{13}$ não levaram diretamente à imigração de haitianos no Brasil. No entanto, esse fenômeno natural está dentre os principais fatores que permitem entender o quarto fluxo de mobilidade haitiana. ${ }^{14}$ Tal como aquelas que se dirigiram a outros

${ }^{13}$ O Conselho de segurança das Nações Unidas decidiu, na sua Resolução de 30 de abril de 2004, "estabelecer, sob o nome de Mission des Nations Unies pour la Stabilisation en Haïti - MINUSTAH, a força de estabilização almejada na sua resolução 1529 (2004), por um período inicial de seis meses que pretende renovar, e solicita que a transferência de poder da Força Multinacional Interina para a MINUSTAH seja feita em 1 de junho de 2004" (ONU, 2004, tradução nossa). Disponível em: <http://www.un.org/fr/documents/view_doc.asp?symbol=S/ RES/1542(2004)>. Acesso em 31/08/2017. A MINUSTAH se estendeu até outubro de 2017, quando "uma nova operação de manutenção da paz no país - Missão das Nações Unidas para o apoio à Justiça no Haiti (MINUJUSTH), composta apenas por civis e unidades de polícia” se estabeleceu. Disponível em: <http://www.defesa.gov.br/relacoes-internacionais/missoes-depaz/o-brasil-na-minustah-haiti> Acesso em 30/01/2018.

${ }^{14}$ As migrações de haitianos relacionadas ao terremoto de janeiro de 2012 não foram somente internacionais. As internas foram, em números, muito maiores do que aquelas que se dirigiram a outros países. É o que apontam os trabalhos de Thomaz (2010), Godoy (2011) e Bersani (2015). Thomaz (2010) e Bersani (2015), sobretudo, evidenciam que o acolhimento a haitianos 
destinos, só é possível entender a emigração de haitianos para a República Federativa do Brasil considerando diversos fatores, humanos na sua maioria, mas também naturais, endógenos e exógenos.

Como mostrado anteriormente, o final da década de 1980 e a década seguinte foram marcadas pela instabilidade política no Haiti, o que justificou intervenções da comunidade internacional. Para Bersani (2015, p.15), "desde o início dos anos 1990, até os dias de hoje, o país vem sendo palco de intervenções pró-desenvolvimento, ou humanitárias, comandadas por organizações internacionais ${ }^{15}$ que insistem em permanecer ali para reconstruir e consolidar o aparato estatal". No tocante à MINUSTAH, que é uma das referidas intervenções internacionais, Thomaz (2010, p.24) afirma que "para a esmagadora maioria dos haitianos, não há nenhuma marca especial: se trata apenas de mais uma missão internacional, como outras que passaram por este país nos últimos dezessete anos”. Segundo o Itamaraty, a participação do Brasil nessa missão aproximou ainda mais o Brasil e o Haiti, dois países que mantêm relações diplomáticas desde 1928. ${ }^{16}$ Nessa aproximação, a dimensão cultural não foi marginalizada

no pós-terremoto de janeiro de 2010 é antes de tudo um assunto interno, um acolhimento de haitianos por haitianos. Aquele que ocorreu entre haitianos fora do país, depois desse terremoto, também é um assunto que merece ser devidamente estudado.

${ }^{15}$ São algumas das Missões das Nações Unidas concluídas no Haiti a United Nations Mission In Haiti - UNMIH (set./1993 - jun./1996), a United Nations Support Mission in Haiti - UNSMIH (jul./1996 - jul./1997), a United Nations Transition Mission in Haiti-UNTMIH (ago. - nov./1997), a United Nations Civilian Police Mission in Haiti - MIPONUH (dez./1997 - mar./2000). Fonte: ONU. Disponível em: <http://www.un.org/en/peacekeeping/missions/past/unmihbackgr1. html>. Acesso em: 30/08/2017.

16 "As relações entre Brasil e o Haiti ganharam grande densidade a partir da decisão brasileira de participar da Missão das Nações Unidas para a Estabilização no Haiti (MINUSTAH), em 2004. O terremoto de 2010, que vitimou mais de 100 mil pessoas e gerou prejuízos equivalentes a 120\% do PIB do país, demandou a intensificação da cooperação brasileira ao desenvolvimento do Haiti. Há iniciativas bilaterais em diversas áreas, dentre as quais destacam-se: [as de] segurança, tanto na atuação MINUSTAH quanto na cooperação para o fortalecimento da Polícia Nacional do Haiti (PNH); econômica, com a ajuda no âmbito do Fundo de Reconstrução do Haiti e outras iniciativas; social, por meio da assistência humanitária e programas de cooperação nas áreas de segurança alimentar, saúde e educação; e político/institucional, pelo intercâmbio de experiências entre os Judiciários brasileiro e haitiano e o apoio ao processo eleitoral e à facilitação do diálogo entre os Poderes constituídos. O Brasil exerce o comando das tropas da MINUSTAH desde sua criação". MRE. República do Haiti. Disponível em < http://www. 
pelo Brasil. Eventos como a organização do “Jogo pela Paz” em 2004 e a inauguração, na capital Porto Príncipe, do Centro de Estudos Brasileiros "Celso Ortega Terra", em 2008, mostram que ela foi levada em conta dentre as estratégias de busca pela paz no Haiti e de visibilização do Brasil naquele país.

Essas intervenções internacionais são justificadas pelo contexto nacional, avaliado como conturbado. Referindo-se aos fatores internos ligados à migração, Handerson (2015) destaca que a insegurança, no sentido amplo da palavra, que afeta a sociedade haitiana, junto com o terremoto de janeiro de 2010, estariam na origem da ampliação deste fenômeno constitutivo da sociedade haitiana. Em suas palavras:

\begin{abstract}
Diante dos diversos tipos de insegurança: pública, política, socioeconômica, alimentícia, educacional, incluindo a área da saúde e do saneamento básico, todas elas em decorrência do quadro empobrecido e precário do Haiti, agravado pela tragédia provocada pelo terremoto de janeiro do referido ano [2010], a mobilidade haitiana ganhou especial significância, volume e crescimento de novos sujeitos e circuitos no espaço migratório internacional. (HANDERSON, 2015, p.73).
\end{abstract}

Dessas inseguranças, a econômica, a política e a social são centrais, e todas ligadas aos fatores que levaram haitianos a emigrarem. No caso da emigração de haitianos para o Brasil, aos fatores de expulsão referidos por Handerson (2015) é preciso acrescentar aqueles comumente chamados de fatores de atração: além das relações entre o Brasil e o Haiti, as experiências migratórias anteriores dos sujeitos, as redes de "coiotes" e também de familiares. As relações entre o Haiti e outros países, que tornam estes mais visibilizados para os haitianos têm seu lugar nessa análise. Com a MINUSTAH, o Brasil ganhou visibilidade, não só perante o Haiti, mas

itamaraty.gov.br/pt-BR/ficha-pais/5221-republica-do-haiti> Acesso em 31 de agosto de 2017. A estreita colaboração ressaltada pelo MRE diverge da análise feita por Seguy (2014), de acordo com a qual era o Haiti que estava ajudando todo mundo, isto é, todos os países colaboradores da MINUSTAH. 
perante o mundo. A relação entre essa Missão e uma boa imagem do Brasil diante dos haitianos e de outras nações participantes é ressaltada por Moreira (2010). Embora a MINUSTAH não tenha diretamente provocado a vinda de haitianos para o Brasil, ela está mesmo assim, na ótica de Patarra (2012) e Cotinguiba (2014), ligada ao afluxo de haitianos para o Brasil nos últimos anos. Por sua vez, Seguy (2014, p.29) sugere que a MINUSTAH é um entre outros instrumentos atuais de colonização do Haiti pelo "capital transnacional", lembrando que "[e]m certos períodos a recolonização é assumida oficialmente, em outros não. (...) [O] que é claro é que o Haiti país independente não passa de uma ilusão". Embora os efeitos da colonização sobre as migrações possam, às vezes, surgir bem depois, a relação entre esses dois fenômenos é demonstrada em Sayad (1998).

A visibilidade do Brasil em escala mundial aumentou ainda mais, sobretudo, a partir de 2010 e gerou, na ótica de Cogo e Badet (2013), aumento do número de imigrantes no país, que se justifica pelo crescimento da economia entre 2010 e 2013 e pela efetivação de obras relativas à organização da Copa do Mundo e dos Jogos Olímpicos (COGO; BADET, 2013). A visibilidade referida coincide com o advento do mais devastador terremoto da história do Haiti, que, como afirmam algumas fontes (THOMAZ, 2010; GODOY, 2011; MORAES et al., 2013; IHSI/BM/DIAL, 2014), abalou profundamente a capital Porto Príncipe, provocando deslocamentos para o interior e para fora do país. De acordo com Godoy (2011), daqueles que se deslocaram (estimados em 661 mil), pelo menos 160 mil se dirigiram rumo à fronteira com a República Dominicana. Dentre eles, milhares de feridos em busca de atendimento no país vizinho.

O Brasil começa a receber haitianos vindos do Haiti em fevereiro de 2010 (COSTA, 2012). A relação entre o terremoto e tanto a migração interna quanto a emigração para a República Dominicana já foi abordada nestas páginas. Com relação ao Brasil, por sua vez, é preciso ressaltar que o referido desastre natural justificaria plenamente o estabelecimento de uma relação direta entre suas consequências e a vinda dos primeiros haitianos que saíram do seu país e adentraram o Brasil: seja de forma indocumentada, 
pela fronteira terrestre da região norte brasileira, seja documentada, como foi, em 2011, o caso dos estudantes selecionados no âmbito do "Programa Emergencial em Educação Superior Pró-Haiti-Graduação"17; e depois de terem potencialmente passado por países como Panamá, Equador, Peru e Bolívia, um percurso referido por diversos estudos (GODOY, 2011; PATARRA, 2012; FERNANDES e CASTRO, 2014; BAPTISTE, 2015) e por pessoas envolvidas no acolhimento a haitianos que foram entrevistadas ${ }^{18}$. Haitianos continuariam vindo para o Brasil se os primeiros que aqui chegaram fossem deportados (ou acolhidos, mas sem direito a nenhum documento)? Passariam por esses países para chegar aqui se antes tivessem conseguido documentos e neles houvesse um crescimento econômico - como era o caso no Brasil - que sugerisse boas expectativas de conseguir trabalho, ter uma boa renda e melhores condições de vida? Conseguiriam entrar no Brasil, mesmo pagando caro a coiotes, se aqui ainda houvesse um anti-haitianismo institucional, como no passado?

Pensando a respeito dos fatores externos que teriam provocado a vinda de haitianos para o Brasil, Fernandes e Castro (2014) assinalam que, em 2010, haitianos poderiam ter preferido migrar para outros países da América do Sul (Argentina, Chile, Equador e Peru), que não lhes teriam exigido visto de entrada em caso de turismo, mas que não o fizeram. Nesse sentido, esses autores ressaltam que a chamada entrada facilitada não basta para explicar a vinda desses haitianos para o Brasil. É preciso assinalar que Handerson (2015) apontou ser o Brasil um lugar de trânsito para alguns desses migrantes iniciais, visto que o destino almejado era a Guiana Francesa. Portanto, buscando identificar os principais motivos que

${ }^{17}$ Este Programa "é coordenado pela Capes, em conjunto com a Secretaria de Educação Superior (SESu) do Ministério da Educação (MEC) e o Ministério das Relações Exteriores (MRE), e foi criado para auxiliar na reconstrução do Haiti, atuando no fortalecimento e na recomposição do Sistema de Educação Superior do país. O programa baseia-se na concessão de bolsas de estudos a estudantes das instituições de ensino superior de Porto Príncipe em instituições de ensino superior brasileiras (IES)". Ver: CAPES, Resultado do Programa Emergencial Pró-Haiti. Disponível em: <http://www.capes.gov.br/cooperacao-internacional/ haiti/pro-haiti>. Acesso em: 31/08/2017.

18 Trata-se de Padre Molinari, em Manaus em 2014; do sociólogo Pereira, em Campinas em 2014; e do Padre Paolo Parise, em São Paulo em 2015. 
atraíram haitianos para o Brasil, aponta-se o crescimento econômico ${ }^{19}$ do país, no momento em que os Estados Unidos da América e demais países desse continente, os países europeus, o Japão, em suma, boa parte dos países do mundo, estavam em plena crise econômica, como um motivo fundamentalmente relevante. Cabe mencionar as falsas promessas de empregos com ganhos de até USD 2.000, em certos casos, feitas por "coiotes" (PATARRA, 2012). Acrescenta-se "o fechamento de alguns países que historicamente mantiveram relações de migração com o Haiti ou talvez até o saturamento, como é o caso da República Dominicana, Equador, Estados Unidos, França [...]”' (OLIVEIRA, 2016, p.129), referido pela pesquisadora Márcia de Oliveira, e sugerido também por Jorge (2014), cujo estudo indica que quase 90\% dos imigrantes da República Dominicana são haitianos. A possibilidade de obter documentos brasileiros é um diferencial na combinação de fatores que atraíram posteriormente milhares de haitianos, como mostrado por Patarra (2012). Conforme essa autora, a regularização dos primeiros haitianos em 2011, com vistos de permanência, "levou à ampliação do número de haitianos que chegavam pela fronteira do Brasil.” (PATARRA, 2012, p.14).

A vinda de haitianos para o Brasil passa a não ser causada apenas por fatores internos ao país caribenho, mas a ser também motivada pelas respostas a sua presença no Brasil, bem como por reações surgidas em destinos anteriores do último fluxo da mobilidade haitiana pelo mundo. Patarra (2012), Fernandes e Castro (2014) e Handerson (2015) assinalaram que houve, depois de 2010, a imigração para o Brasil de haitianos que residiam em países como a República Dominicana e a Venezuela. A possibilidade de chegar ao Brasil com grande expectativa de ganhar salários altos até para o padrão brasileiro, de obter quase imediatamente uma documentação, mesmo provisória, ou de imigrar já com o Visto Humanitário, emitido no Haiti ou em alguns outros países ${ }^{20}$, que garantisse

\footnotetext{
${ }^{19}$ Lembrando que Cogo e Badet (2013) o citam entre as justificativas do aumento de imigrantes no Brasil nos últimos anos.

${ }^{20}$ Foram países onde o Visto Humanitário podia ser emitido: a República Dominicana, Peru, Equador e Panamá (CONECTAS DIREITOS HUMANOS). Disponível em: <www.conectas. org >. Acesso em: 06/02/2015. O objetivo principal do Visto Humanitário, que é pôr fim à
} 
o direito de trabalhar e de usufruir de serviços públicos como os de saúde, por exemplo, são outros fatores ligados ao Brasil que mobilizaram muitos haitianos.

As causas, bem como os caminhos, da imigração de haitianos no Brasil são múltiplas. Neste processo migratório, a comunicação entre os próprios haitianos situados em diferentes localidades, como no Haiti, no Brasil, no trajeto e em outros países, bem como o apoio por eles recebido, que inclui o acolhimento de haitianos por seus conterrâneos, além das decisões que decorrem dessa comunicação entre familiares, embora apenas mencionadas aqui, ocupam um lugar central nas razões para migrar, de acordo com o entrevistado Pereira (2014), e também com Handerson (2015). Pergunta-se a seguir como são acolhidos os haitianos no Brasil.

\section{ACOLHIMENTO E CONDIÇÕES DE EXISTÊNCIA DE HAITIANOS NO BRASIL}

Se Sayad (1998, p.16) diz que "a imigração é um fato social completo", o acolhimento a imigrantes ou estrangeiros, de modo geral, é também uma questão altamente complexa. ${ }^{21}$ Pereira (2016, p.102) afirma que "como questão humanitária, social e política, a acolhida tornase complexa e desafiadora à medida que se multiplica, se diversificam, tornam-se cada vez mais as migrações [...] nesse primeiro quadrante do século XXI". Portanto, pretende-se tratar apenas, nesse caso, de alguns dos seus aspectos, notadamente políticos, econômicos e institucionais. No tocante ao acolhimento a haitianos no Brasil, o Visto Humanitário não é o primeiro sinal institucional público diante de sua mobilidade espacial.

imigração indocumentada de haitianos e formalizar a vinda de haitianos ao Brasil, foi muito mais visível no último bimestre de 2015, quando se observou que quase todas as entradas no país foram por via aérea, que pressupõe visto. (DEPARTAMENTO DE POLÍCIA FEDERAL, ATÉ 20/03/20116 apud CONARE, 2016, p. 4). Disponível em: <http://pt.slideshare.net/ justicagovbr/sistema-de-refgio-brasileiro-balano-at-abril-de-2016>. Acesso em: 13/05/2016. Este visto expressa também o compromisso do Brasil de combater as quadrilhas de coiotes e ressalta o caráter acolhedor do país perante cidadãos do Haiti.

${ }^{21}$ Essa complexidade do acolhimento a estrangeiros é mostrada na obra dirigida por Alain Montandon: O livro da Hospitalidade: acolbida do estrangeiro na história e nas culturas. São Paulo: Editora Senac, 2011. 
Pode-se afirmar que o afluxo migratório de haitianos para o Brasil a partir de 2010 encontra uma política de acolhimento institucional cuja compreensão se faz necessária para melhor analisar esse acolhimento, particularmente entre 2010 e 2011, quando ainda não existia o referido Visto Humanitário, exclusivo para haitianos que desejassem vir ao Brasil. De acordo com Patarra (2012, p.13), essa imigração foi marcada pelo seu ingresso indocumentado no Brasil, e "o caso da vinda de haitianos para o Brasil se reveste de especial importância, pois desde o fim da $2^{\text {a }}$ Guerra Mundial não se via no país um afluxo tão expressivo de imigrantes, originários do Hemisfério Norte, que chegaram ao país em situação migratória indocumentada".

O acolhimento institucional, público ou não, oferecido aos primeiros haitianos no bimestre inicial daquele ano foi, como dito anteriormente, importante para situar o Brasil como um novo destino, que se tornou, em poucos anos, o quarto grande fluxo da emigração haitiana. Quando se olha justamente para as políticas migratórias europeias e da América do Norte, cada vez mais restritivas até mesmo com relação a solicitações de refúgio, e também para a nebulosa situação jurídica de haitianos e seus descentes na República Dominicana, discutida por Jorge (2014), compreende-se a busca por novos horizontes, "a diversificação das rotas migratórias que questionam noções estáticas como 'país de origem', 'país de destino' ou ainda migrações do 'Sul para o Norte' do mundo" (PEREIRA, 2016, p.102), bem como a afirmação de Barreto (2010) de que a legislação brasileira de Refúgio (Lei $N^{\circ}$ 9474, de 1997) em vigor é reconhecida como avançada pelas Nações Unidas.

Uma vez na fronteira da região norte do país, os primeiros haitianos que ali chegaram solicitaram refúgio. Tais solicitações foram registradas e encaminhados pela Polícia Federal ao Comitê Nacional para Refugiados (CONARE), órgão do Ministério de Justiça responsável por sua análise (PATARRA, 2012). Os pedidos dessa natureza dão aos solicitantes o direito de tirar a carteira de trabalho e trabalhar legalmente no Brasil. É cabível supor que, se no lugar de uma legislação de refúgio avançada, que respeita a humanidade dos solicitantes dessa condição - respeito que se traduz em possibilidade de aquisição imediata de documentação provisória, em direito 
de circular livremente e de trabalhar legalmente no território nacional houvesse medidas repressivas como detenções provisórias, devoluções ou não recebimento dos pedidos de refúgio, o afluxo cessaria precocemente. Mas caberia a algum país participante da MINUSTAH adotar tais medidas severas diante de pedidos de refúgio de cidadãos de um Estado palco de intervenção internacional para estabilizá-lo?

Os primeiros momentos de chegada pelo norte brasileiro, principalmente pelo Acre e Amazonas, foram desafiadores seja para o Estado (no caso do Acre) seja para os scalabrinianos da Igreja Católica em Manaus. ${ }^{22}$ A situação dos abrigos, em que foram alojados aqueles que demandavam tais serviços, foi um meio para veicular a imagem de uma imigração de "miseráveis" e, portanto, de um Brasil que estaria acolhendo "a miséria alheia". De acordo com Portes (1999), em matéria de migração, os mais pobres não tomam a dianteira do processo. Aquelas situações de carência nos abrigos, bastante exploradas pela mídia (TÉLÉMAQUE, 2012), e que, a nosso ver, contribuíram neste caso para que se subestimasse a oferta de trabalho e consequentemente o salário proposto a esses migrantes ${ }^{23}$, estavam ligadas, na ótica de Patarra (2012), à pouca infraestrutura dos municípios diante de uma crescente demanda por atendimento de imigrantes. Acrescentemos a isso as difíceis condições de travessia, que custava muito mais caro do que uma viagem regular. Segundo o jornal O Estado de S. Paulo, em 2015 a Agência Brasileira de Inteligência - ABIN estimou em US\$ 60 milhões o faturamento dos coiotes com a imigração de haitianos. ${ }^{24}$ Contar com essas caras e perigosas redes exploradoras de migrantes remete tacitamente às boas expectativas destes sujeitos com relação a seus destinos, e também ao rigor das políticas migratórias dos países almejados.

22 Patarra (2012) e Handerson (2015) mostram a função central da Pastoral da Mobilidade Humana no processo de acolhimento a haitianos no Brasil.

23 Os modestos salários desses trabalhadores imigrantes remetem também aos históricos índices de pobreza da população negra brasileira referidos por Silva (2013).

${ }^{24}$ Ver: O Estado de São Paulo: Rede de 'coiotes' já faturou US\$ $60 \mathrm{mi}$ com haitianos, diz relatório. Publicado em 23/05/2015. Disponível em: <http://brasil.estadao.com.br/noticias/ geral,rede-de-coiotes-ja-faturou-us-60-mi-com-haitianos-diz-relatorio,1692709>. Acesso em: $31 / 08 / 2017$. 
Em menos de dois anos de imigração, "de acordo com os dados da Coordenação Geral do Comitê Nacional para Refugiados (CONARE), 2.186 haitianos ingressaram no Brasil e solicitaram refúgio, desde o terremoto de janeiro de 2010 até setembro de 2011" (GODOY, 2011, p.47). Dois anos depois Moraes et al. (2013) assinalam que o Ministério de Relações Exteriores brasileiro estimava que havia mais 10.000 haitianos no Brasil, sendo mais da metade deles portadores de vistos de permanência até junho de 2013.

É fundamental destacar que as solicitações de refúgio formuladas por haitianos e encaminhadas ao CONARE pelas autoridades na fronteira não eram deferidas por este Comitê (PATARRA, 2012), visto que para o Estado brasileiro a causa principal da migração era ambiental, não política, e nem de outra natureza que fosse contemplada pela Convenção de Genebra de 1951. Segundo Patarra (2012), não sendo possível atendê-los conforme essa Convenção, suas solicitações foram sendo encaminhadas, como previsto pela lei, para o Conselho Nacional de Imigração (CNIg) para serem apreciadas numa ótica humanitária. A regularização da situação dessas pessoas por razões humanitárias pelo CNIg se baseou na Resolução Recomendada $n^{\circ}$ 08/06 e iniciada em março de 2011, quando 199 haitianos obtiveram visto permanente. Em novembro de 2015, o governo brasileiro tornou público o fato de ter regularizado a situação de estadia de 43.871 haitianos que entraram sem visto pela região norte do Brasil desde 2010, e que tinham "documentos provisórios de solicitação de refúgio". Junto a esse mecanismo de regularização, foi criada em 12 janeiro de 2012, pelo CNIg, a Resolução Normativa N 97, especialmente destinada à criação de um visto especial para haitianos, essencialmente por razões humanitárias. No seu parágrafo único, esse documento oficial ressalta que "consideram-se razões humanitárias, para efeito dessa Resolução Normativa, aquelas resultantes do agravamento das condições de vida da população haitiana em decorrência do terremoto ocorrido naquele país em 12 de janeiro de 2010". Com isso, o Estado brasileiro admite claramente a relação entre o terremoto de 2010 e a imigração haitiana no Brasil, além de reconhecer indiretamente as difíceis condições de vida antes do advento do referido terremoto. Ademais, ele assume oficialmente o compromisso 
de receber regularmente haitianos que desejarem vir do Haiti para residir no país, porém condicionados a renovar sua situação de estadia mediante comprovação de vínculo laboral. Cabe ressaltar que, para Pereira (2016, p.118), emigrar "é um direito previsto na declaração Universal de Direitos Humanos de 1948 e em vários tratados internacionais. No entanto, imigrar ou entrar em um país não é um direito previsto em nenhuma declaração ou tratado de direitos internacionais." Reis (2007) também destacou que receber ou não estrangeiros em seu território é privilégio dos Estados.

O acolhimento institucional público a migrantes em questão sofreu alterações, notadamente com a anulação, em 2013, da cota de 1.200 vistos por ano estabelecida quando autorizada pela $\mathrm{RN} \mathrm{N}^{\circ} 97$ a criação do Visto Humanitário em 2012, ${ }^{25} \mathrm{com}$ a descentralização dos locais de solicitação tanto deste Visto no Caribe e na América do Sul quanto da Carteira de Trabalho, com a criação de estabelecimentos voltados para o público imigrante, ${ }^{26} \mathrm{com}$ as discussões em âmbito nacional relativas a imigrações, além de com a adoção de uma nova Lei de Migração brasileira, sancionada em junho de 2017 pelo Presidente da República, cuja elaboração levou de alguma forma em conta as propostas dos próprios imigrantes, de modo a substituir o tão criticado Estatuto do Estrangeiro de 19 de agosto de 1980. Essa nova Lei reconhece e considera a migração na perspectiva de Direitos Humanos.

Como amplamente sabido, a imigração de haitianos no Brasil é fortemente associada ao trabalho, tanto na ótica dos representantes das instituições públicas envolvidas no acolhimento de imigrantes, como na de pesquisadores sobre o tema, que lograram recolher informações junto aos haitianos. Quando entrevistado em 21 de janeiro de 2015, o então presidente do CNIg, Paulo Sérgio de Almeida, disse que, de forma

25 Não tendo suscitado imediatamente os efeitos esperados, a $\mathrm{RN} \mathrm{N}^{\circ} 97$ foi criticada, particularmente no que tange ao teto de vistos fixado por ano. As críticas contribuíram para a retirada deste e para a prorrogação da vigência dessa $\mathrm{RN}$.

${ }^{26}$ Essas ações não são necessariamente federais. Algumas delas ocorreram apenas em determinadas cidades, como São Paulo, por exemplo, onde foi criado em 2014 o Centro de Referência e Acolhida para Imigrantes (CRAI). Pereira fala da criação, nessa cidade, da Lei Municipal de Migração (LEI No 16.478/2016), que "prevê a facilitação para os processos de acolhida e inserção social do migrante [...]” (PEREIRA, 2016, p.106). 
geral, as haitianas não procuram trabalhos industriais que exigem força física, nos quais seus compatriotas encontram trabalho. Ele afirma que a imigração para o Brasil é uma migração em busca de trabalho. Sendo assim, um dos espaços destacados para o acolhimento a haitianos no país é o mercado de trabalho nacional. Este acolheu formalmente milhares de haitianos ao longo dos anos. De acordo com Oliveira (2016) e Cavalcanti (2014), os haitianos constituíram a principal nacionalidade, em 2013, no mercado formal de trabalho brasileiro. Essa posição foi mantida até o ano 2015, quando representavam 26,4\% (OLIVEIRA, 2016, p.60). Os dados do Ministério do Trabalho mostram que, das 169.506 carteiras de trabalho emitidas entre 2010 e 2015, 49.155 eram de nacionais do Haiti, o que representa $29 \%$ do total.

De modo geral, o efetivo de imigrantes no mercado de trabalho formal brasileiro teve um aumento expressivo, quando se compara os anos de 2010 e 2015. De um total de 54.333 em 2010, passou-se para $125.535 \mathrm{em}$ 2015 (OLIVEIRA, 2016, p.70). Esse cenário mostra que o capital nacional e estrangeiro, no Brasil, necessitava da força de trabalho estrangeira, que foi efetivamente empregada em diversas atividades necessárias para sua dinâmica.

Sayad (1998) diz que o trabalho justifica a migração e também a permanência do migrante no lugar de instalação. Segundo ele, a comprovação de residência é também imprescindível para arrumar trabalho. Se a migração dos últimos anos para o Brasil é, como foi dito anteriormente, uma migração para trabalho, o impacto dos trabalhadores haitianos sobre as estatísticas relativas à força de trabalho estrangeira no Brasil nos últimos anos é mais do que esperado, pois para essa nacionalidade, muitos são beneficiários do Visto Humanitário, cuja renovação depende da situação laboral de seu detentor. Este aumento é nítida e fortemente influenciado pela entrada de haitianos no mercado de trabalho formal brasileiro.

Porém, o Brasil que acolheu formalmente milhares de imigrantes em seu mercado de trabalho também atravessa nos últimos tempos uma crise econômica que causa desemprego para milhões de brasileiros. No tocante aos imigrantes, o estudo de Cavalcanti et al. (2016) mostrou que no primeiro semestre de 2016, ao contrário do saldo Admissão $X$ demissão de 
haitianos, positivo em 2015, o desemprego afetou claramente esse grupo de modo geral, mas também os trabalhadores imigrantes de nacionalidade haitiana. Esses ficaram com saldo negativo de -3.259 na relação admitidos/ demitidos. É o maior saldo negativo, seguido respectivamente pelo de argentinos (-182), portugueses (-166) e senegaleses (-164). O mercado de trabalho formal, no qual os haitianos se destacaram de 2013 a 2015, foi também o que demitiu posteriormente milhares de trabalhadores haitianos, gerando um saldo negativo para essa nacionalidade muito maior que o de outras consideradas pelo estudo de Cavalcanti et al. (2016). Ainda de acordo com este estudo, a média salarial de haitianos no momento da admissão e da demissão no mercado de trabalho no primeiro semestre de 2016 era de, respectivamente, $\mathrm{R} \$ 1.101$ e de $\mathrm{R} \$ 1.183 .{ }^{27}$

Neste mesmo período, as principais ocupações que mais admitiram estrangeiros foram respectivamente: Servente de Obras, Alimentador de Linha de Produção, Faxineiro, Cozinheiro Geral, Pedreiro, Abatedor, dentre outras. No mesmo sentido, aquelas em que estrangeiros foram mais demitidos foram, respectivamente: Servente de Obras, Alimentador de Linha de Produção, Faxineiro, Pedreiro, Magarefe, Abatedor, Cozinheiro em Geral (CAVALCANTI et al., 2016). Estes postos relativamente marginais não costumam ser os mais almejados pelos trabalhadores nacionais, e certamente por isso concentram altos percentuais de migrantes.

$\mathrm{O}$ acolhimento a trabalhadores imigrantes de forma geral, e haitianos em particular, deve reconhecimento às ações de acolhimento promovidas principalmente pelos scalabrinianos, seja em Manaus ou na cidade de São Paulo, para citar apenas dois exemplos. O caso do acolhimento oferecido pela Missão Paz a haitianos na capital paulista contribuiu não só para a formalização dos vínculos laborais, como também para valorizar um pouco mais o trabalho dos migrantes, para prevenir situações de exploração de trabalhadores imigrantes, para o conhecimento da lei e da cultura brasileiras, para entender que a migração é um fenômeno

${ }^{27} \mathrm{Na}$ admissão, ela era menor que a de senegaleses ( $\left.\mathrm{R} \$ 1.122\right)$, argentinos ( $\left.\mathrm{R} \$ 1.227\right)$, paraguaios ( $\mathrm{R} \$ 1.150)$ e bolivianos $(\mathrm{R} \$ 1.249)$, mas na demissão era maior que a de senegaleses (R\$ 1.171) e de paraguaios (R\$1.169) (CAGED/CTPS - MINISTÉRIO DO TRABALHO apud CAVALCANTI et al., 2016, p. 123).

Temáticas, Campinas, 25, (49/50): 17-48, fev./dez. 2017 
humano tanto antigo quanto muito atual, sobre o qual as autoridades públicas devem se preocupar no intuito de promover políticas públicas voltadas para os migrantes, considerando barreiras socioinstitucionais recorrentes, tais como o preconceito, a negrofobia, a desconsideração de suas competências, o racismo, o abuso de poder, as dificuldades de acesso à documentação, à justiça, a serviços públicos de saúde, à educação, formação e aos trabalhos decentes e dignamente remunerados.

É preciso dizer que as médias salariais referidas anteriormente não distinguem a situação de homens e de mulheres. Padres envolvidos no acolhimento a haitianos ${ }^{28}$ - e de outros imigrantes - entrevistados respectivamente em novembro de 2014 e 2015 em Manaus e São Paulo afirmaram que os desafios para a inserção laboral das mulheres era bem maior, não só por causa da pouca oferta de vagas para elas, mas também porque, no caso de Manaus, o mercado que a elas se abriu era dos menos esperados e procurados por essas: o de trabalho doméstico.

Sem o acolhimento e orientação dos scalabrinianos, poder-se-ia esperar que, mesmo os portadores do Visto Humanitário acabassem mais expostos a situações abusivas e de exploração, pois, como afirma o padre Molinari, ${ }^{29}$ a respeito das empresas que iam para a Paróquia contratar trabalhadores haitianos: "não tem empresa capitalista que visa dar bemestar. Elas visam lucro, precisam de mão-de-obra. Quanto mais mão de obra tiver e quanto mais ela for barata, melhor é". Mas como considerar a ajuda dada pelos migrantes a seus próprios familiares diante dessas condições?

Sem o trabalho de informação, mediação e negociação entre empregadores e trabalhadores imigrantes do Haiti, no caso de São Paulo, por exemplo, a inserção laboral e social desses imigrantes, que ocorreu na periferia do mercado de trabalho, seria ainda mais precária, colocando em risco o caráter humanitário, o que se liga tanto à regularização daqueles que entraram pelo norte, quanto à vinda de haitianos autorizados por razões humanitárias mediante visto. Por outro lado, sem a regularização

\footnotetext{
${ }^{28}$ Trata-se dos Padres Paolo Parise, da Missão Paz, em São Paulo, e Valdecir Molinari, da Paróquia São Geraldo, em Manaus.

${ }^{29}$ Entrevistado pelo pesquisador em 5 novembro de 2014 em Manaus.
} 
proporcionada pelo documento oficial de identidade, várias iniciativas da sociedade civil poderiam esbarrar em vários obstáculos. Por exemplo, negociar uma pequena elevação do salário dos migrantes depende da possibilidade de registrar o resultado do acordo em Carteira de Trabalho e Previdência Social.

Os desafios anteriormente referidos, que se colocam (não só) aos haitianos no Brasil, não dependem do tipo de Resolução mobilizada para permitir que residam no Brasil. Foi possível perceber que cidadãos do Haiti no Brasil não foram poupados nem pelo desemprego, nem de se situar na periferia do mercado oficial de trabalho, o que significa que migrações tanto internas, já assinaladas por Baeninger e Peres (2015), para localidades consideradas mais favoráveis, quanto internacionais, de haitianos que já estavam no Brasil, e referidas por Lauro Bocchi, ${ }^{30}$ continuam ocorrendo. Ademais, cabe destacar que o desafio de encontrar emprego nos tempos de crise econômica colocam seriamente em risco a possibilidade de renovação de visto para imigrantes portadores do visto humanitário.

\section{CONSIDERAÇÕES FINAIS}

A história das migrações haitianas é secular e bastante complexa. Como disse Handerson (2015), a migração é parte constitutiva da sociedade haitiana. Considerando a eliminação dos povos indígenas que ali residiam antes da chegada dos europeus, a história que se conhece depois disso é estreitamente vinculada às migrações, seja antes ou depois de sua independência política. Ela está ligada não só à economia, mas também à política, à raça, à colonização, ao meio ambiente e também à cultura.

O território que hoje é a República do Haiti recebeu numerosos europeus, africanos, asiáticos e também americanos, sobretudo antes de conquistar sua independência política. Considerando o ano de 1804

\footnotetext{
${ }^{30}$ Lauro Bocchi, diretor do CIBAI MIGRAÇÕES, afirma que "ultimamente se fala em 10.000 haitianos que deixaram o Brasil, não necessariamente voltaram para o Haiti. Buscaram outros países". Ver Jornal Zero Hora: Sonhos partidos. Publicado em: 02/10/2015. Disponível em: <http://videos.clicrbs.com.br/rs/zerohora/video/geral/2015/10/sonhospartidos/137856/>. Acesso em: 06/10/2015.
} 
como marco divisório, caberia dizer que dessa data aos dias de hoje o Haiti passou a ser mais um país de emigração do que de imigração, sendo o inverso no período em que era colônia. Se os haitianos emigraram para diversos destinos antes e durante o século XVIII e desde então, Cotinguiba (2014, p.83) sublinhou, contudo, que "a emigração só se torna um fenômeno social no país a partir do século XX e isso se justifica, em parte, por questões econômicas e políticas consideradas desastrosas para o país". Os motivos na base das emigrações de haitianos variam de um fluxo para outro e também dentro de cada um dos quatro grandes fluxos, cujos destinos foram a República Dominicana e Cuba, os Estados Unidos e o Canadá e Brasil. Podem ser tanto endógenos quanto exógenos, ou mesmo uma combinação de ambos. A colonização, a influência cultural, a proximidade geográfica, a economia, a política de acolhimento institucional a imigrantes ou solicitantes de refúgio, a situação ambiental, a instabilidade política são alguns deles.

No que tange à vinda de haitianos para o Brasil a partir de 2010, último grande fluxo e objeto de análise mais detida neste artigo, a dimensão ambiental é destacada, mas sabe-se que a economia e a política são centrais neste processo. Embora tenham sido acolhidos no Brasil por razões humanitárias, boa parte dos haitianos depende da condição laboral, da capacidade comprovada de contribuir para o desenvolvimento do Brasil para aqui permanecer regularmente, e está, em conjunto com outros migrantes, em postos de trabalho pouco almejados por trabalhadores nacionais, além de receberem remuneração modesta. Neste sentido, a contribuição destes migrantes ao desenvolvimento poderia ser maior se a eles se abrissem mais oportunidades que considerassem suas competências.

No primeiro semestre de 2016, o desemprego, que já os vinha afetando, ultrapassou as admissões no mercado de trabalho brasileiro. Em termos de rendas baixas, o caso das haitianas é ainda mais emblemático. Foi possível observar em estudo anterior que, no geral, seus empregadores colocam os imigrantes negros em posições socialmente reservadas aos negros brasileiros, o que faz com que, muitas vezes, as competências destes trabalhadores migrantes não cheguem a ser sequer avaliadas, pois os trabalhos a que são direcionados não exigem muitas habilidades, 
mas apenas resistência física, apesar de o acolhimento ser oficialmente embasado em razões humanitárias. Com efeito, oficialmente o caráter humanitário está mais ligado à forma de ingressar e à regularização da estadia de quem ingressou sem documentação brasileira. A RN N 97 de 2012, uma medida salutar e exemplar de acolhimento de migrantes negros na história das migrações, não poupou seus beneficiários de sofrerem atos racistas, do desemprego, dos modestos salários, nem das dificuldades de inserção no mercado de trabalho, sobretudo para as mulheres.

As ações de acolhimento institucional público ganharam em qualidade com o passar do tempo. De um acolhimento tímido e pontual entre 2010 e 2011, chegou-se a uma oficialização da abertura do Brasil para receber haitianos, até sua ampliação, em 2013. O acolhimento promovido pelos scalabrinianos a haitianos ocupa um lugar central neste processo de receber imigrantes com humanidade e respeito por ser notadamente abrangente, dinâmico e aberto às necessidades e solicitações dos migrantes.

\section{REFERÊNCIAS BIBLIOGRÁFICAS}

BAENINGER, Rosana; PERES, Roberta Guimarães. SOS Português: imigração haitiana em São Paulo. $39^{\circ}$ Encontro anual da ANPOCS. GT 23 Migrações Internacionais: Legislações. Estados e Atores Sociais. Caxambu, 2015.

BAPTISTE, Chandeline Jean. Transição para a vida adulta e migração internacional: o caso dos jovens haitianos na cidade de São Paulo. Campinas, Dissertação (Mestrado em Demografia) - Instituto de Filosofia e Ciência Humanos, Universidade Estadual de Campinas, 2015.

BARRETO, Luiz Paulo Teles Ferreira. A Lei Brasileira de Refúgio - Sua história. In: BARRETO, Luiz Paulo Teles Ferreira (Org.). Refúgio no Brasil: a proteção brasileira aos refugiados e seu impacto nas Américas. 1.ed. Brasília: ACNUR, Ministério da Justiça, p.12-21, 2010. Disponível em: <http://www.migrante.org.br/migrante/images/arquivos/ refugio-no-brasil.pdf $>$. Acesso em: 15/05/2015. 
BASSO, Pietro. Imigração na Europa. In: ANTUNES, Ricardo (Org.). Riqueza e miséria do trabalho no Brasil II. São Paulo: Boitempo, p.29-41, 2013.

BERSANI, Ana Elisa. O (extra)ordinário da ajuda: histórias não contadas sobre desastre e generosidade na Grand'Anse, Haiti. Campinas, Dissertação (Mestrado em Antropologia) - Instituto de Filosofia e Ciência Humanos, Universidade Estadual de Campinas, 2015.

CAVALCANTI, Leonardo. et al. A movimentação dos imigrantes no mercado de trabalho formal: admissões e demissões. In: CAVALCANTI, Leonardo et al. (Org.). A inserção dos imigrantes no mercado de trabalho brasileiro. Relatório Anual 2016. Observatório das Migrações Internacionais; Ministério do Trabalho/Conselho Nacional de Imigração e Coordenação Geral de Imigração. Brasília, DF: OBMigra, p.74-125, 2016.

CAVALCANTI, Leonardo. Imigração e mercado de trabalho no Brasil. Características e tendências. In: CAVALCANTI, Leonardo et al. (Org.). A Inserção dos Imigrantes no Mercado de Trabalho Brasileiro. Brasília: Cadernos do Observatório das Migrações Internacionais, p.11-22, 2014. Disponível em: <http://portal.mte.gov.br/obmigra/home. htm>. Acesso em: 12/01/2015.

COMITÊ NACIONAL PARA REFUGIADOS. Sistema de Refúgio brasileiro, desafios e perspectivas, 2016. Disponível em: <http:// pt.slideshare.net/justicagovbr/sistema-de-refgio-brasileiro-balanoat-abril-de-2016>. Acesso em: 13/05/2016.

CONECTAS DIREITOS HUMANOS. Resposta a pedido de acesso à informação. Número do protocolo do pedido: 09200000325201333. 15/08/2013. Disponível em: <www.conectas.org>. Acesso em: $06 / 02 / 2015$.

COORDENAÇÃO DE APERFEIÇOAMENTO DE PESSOAL DE NÍVEL SUPERIOR. Resultado do Programa Emergencial PróHaiti. 2011. Disponível em: <http:/ /www.capes.gov.br/cooperacaointernacional/haiti/pro-haiti>. Acesso em: 31/08/2017. 
COSTA, Gelmino A. Haitianos em Manaus: Dois anos de imigração - e agora! Travessia: Revista do migrante. CEM - Ano XXV, n. 70, p.91-97, 2012.

COTINGUIBA, Geraldo Castro._Imigração haitiana para o brasil: a relação entre trabalho e processos migratórios. Rondônia, Dissertação (Mestrado em História e Estudo Culturais) - Fundação Universidade Federal de Rondônia, 2014.

DUROUX, Rose. Imigração. França/Europa. In: MONTANDON, Alain (dir.). O livro da Hospitalidade: acolhida do estrangeiro na história e nas culturas. Editora Senac São Paulo, p.1051-1078, 2011.

FERNANDES, Duval; CASTRO, Maria da Consolação. Projeto: Estudos sobre a migração haitiana ao Brasil e diálogo bilateral. Belo Horizonte, 2014.

GALEANO, Eduardo. La maldición blanca. In: República Dominicana y Haiti: El derecho a vivir. Fundación Juan Bosch. Santo Domingo, República Dominicana, p.459-463, 2014.

GODOY, Gabriel Gualano de. O caso dos haitianos no Brasil e a via da proteção humanitária complementar. In: RAMOS, André de Carvalho et al. 60 anos de ACNUR, Perspectivas de futuro. São Paulo, p.45-68, 2011.

HAITI-REFERENCE. Un Guide de Référence sur Haiti. Disponível em: <http://haiti-reference.com/pages/>. Acesso em: 30/08/2017.

HALL, Stuart. "Pensando a Diáspora: reflexões sobre a terra no exterior". In: HALL, Stuart - Da Diáspora: Identidades e mediações culturais. Belo Horizonte: Editora UFMG, Brasília: Representação da UNESCO, p.25-50, 2003.

HANDERSON, Joseph. Diáspora: As dinâmicas da mobilidade haitiana no Brasil, no Suriname e na Guiana Francesa. Rio de Janeiro, Tese (Doutorado em Antropologia Social) - Museu Nacional, Universidade Federal de Rio de Janeiro, 2015. 
IHSI/BANQUE MONDIALE/DIAL. Enquête sur les Conditions de Vie des Ménages Après Séisme (ECVMAS 2012): Synthèse des premiers résultats. 2014.

JORGE, Otávio Calegari. Codemò: escravos sem grilhões: vida operária ao redor da zona franca CODEVI em Ouanaminthe, Haiti. Campinas, Dissertação (Mestrado em Sociologia). Instituto de Filosofia e Ciência Humanos, Universidade Estadual de Campinas. 2014.

MONTANDON, Alain (dir.). O livro da Hospitalidade: acolbida do estrangeiro na história e nas culturas. Editora Senac São Paulo, 2011.

MORAES, Isaias Albertin de et al. A imigração haitiana para o brasil: causas e desafios. In: Revista Conjuntura Austral, v. 4, n. 20, 2013, p.95-114. Disponível em: <http://seer.ufrgs.br/index.php/ ConjunturaAustral/article/download/35798/27329>. Acesso em: 15/01/2015.

MOREIRA, Luciano Rodrigues. Combate de paz: São Paulo: Baraúna, 2010.

OLIVEIRA, Márcia. Entrevista concedida a Kassoum Diémé. Por que falar de imigração no Brasil? TRAVESSLA, revista do migrante. Publicação do CEM - Ano XXIX, n. 79, p.127-132, 2016.

PATARRA, Neide Lopes. Brasil: país de imigração? In: e-metropolis n. 09. Ano 3 | junho de 2012, p.6-18. Disponível em: <http:/ / emetropolis. net>. Acesso em: 08/10/2015.

PEREGALLI, Enrique. América que os europeus encontraram. São Paulo: Editora Atual, 1998.

PEREIRA, José Carlos. Acolhida a imigrantes e refugiados: a ética da pastoral do migrante e desafios para a democracia no Brasil. TRAVESSLA, revista do migrante. Publicação do CEM - Ano XXIX, n. 79, p.101-126, 2016.

PORTES, Alejandro. Migrações Internacionais: Origens, Tipos e Modos de Incorporação. Portugal: Celta Editora. 1999. 
PRESIDÊNCIA DA REPÚBLICA; CASA CIVIL. Lei no 9.474, de 22 de julho de 1997. Disponível em: <http://www.planalto.gov.br/ ccivil_03/Leis/L9474.htm>. Acesso em: 13/05/2016.

REIS, Rosana Rocha. Políticas de imigração na França e nos Estados Unidos (1980-1998). São Paulo: Aderaldo \& Rothschild, 2007.

SASSEN, Saskia. Mondialisation et géographie globale du travail. In: FALQUET, Jules et al. (dir.). Le sexe de la mondialisation. Genre, classe, race et nouvelle division du travail. Editions Sciences Po Les Preses, Paris, p.27-41, 2010.

SAYAD, Abdelmalek. A imigração ou os paradoxos da alteridade. São Paulo, 1998.

SCARAMAL, Eliesse dos Santos Teixeira. Haiti: fenomenologia de uma barbárie. Goiânia: Cânone Editorial, 2006.

SEGUY, Franck. Catástrofe de janeiro de 2010, a "internacional comunitária" e a recolonização do Haiti. Campinas, Tese (Doutorado em Sociologia) Instituto de Filosofia e Ciências Humanas, Universidade Estadual de Campinas, 2014.

SILVA, Tatiana Dias. Mulheres negras, pobreza e desigualdade de renda. In: MARCONDES, Mariana Mazzini et al. (Org.). Dossiê mulheres negras: retrato das condições de vida das mulheres negras no Brasil. Brasília: Ipea, p.109-131, 2013.

STATISTIQUE CANADA. La communauté haïtienne au Canada, 2001. No CS89-621/12-2007F- Disponível em: <http://publications. gc.ca/collections/collection_2007/statcan/89-621-X/89-621XIF2007011.pdf>. Acesso em: 08/08/2015.

TÉLÉMAQUE, Jenny. Imigração haitiana na mídia brasileira: entre fatos $e$ representações. Rio de Janeiro, Monografia (Graduação em Comunicação Social: Publicidade e Propaganda) - Escola de Comunicação, Universidade Federal do Rio de Janeiro, 2012. 
THOMAZ, Omar Ribeiro. O terremoto no Haiti, o mundo dos brancos e o Lougawou. In: Novos Estudos, n.86, 2010. Disponível em: <http:/ www.scielo.br/pdf/nec/n86/n86a02.pdf>. Acesso em: 08/07/2015.

VILLA, Miguel. Una nota acerca del proyecto de investigación sobre migración internacional en Latinoamerica - IMILA. In: PATARRA (Coor.). Emigração e imigração internacionais no Brasil contemporâneo. Campinas: FNUAP, p.107-124, 1996. 